\title{
Source-Sink Dynamics: a Neglected Problem for Landscape-Scale Biodiversity Conservation in the Tropics
}

\author{
James J. Gilroy ${ }^{1}$ • David P. Edwards ${ }^{2}$
}

Published online: 11 February 2017

(C) Springer International Publishing AG 2017

\begin{abstract}
Ecologists have long recognised that populations can persist in poor-quality habitats with below-replacement population growth rates ('sinks') provided there is continual immigration from areas with positive intrinsic growth ('sources'). Source-sink dynamics complicate the assessment of species-environment relationships, because species' presence or density can be poorly correlated with underlying population productivity. Yet, applied conservation research often uses presence or abundance data to assess species responses to environmental change, particularly in the tropics where few long-term ecological studies are established. This approach assumes that abundance data reliably indicate habitat quality, but in sinks, this assumption can be violated. We review the recent literature and identify a regional bias in reporting of source-sink phenomena, with $71 \%$ of the 210 studies considered coming from temperate regions, particularly Eurasia and North America. Very few studies come from tropical and subtropical biomes, where human-driven biodiversity loss is occurring most rapidly, with over $80 \%$ not providing strong evidence in the form of demographic, dispersal or molecular data.
\end{abstract}

This article is part of the Topical Collection on Scale-Measurement Influence, and Integration

Electronic supplementary material The online version of this article (doi:10.1007/s40823-017-0023-3) contains supplementary material, which is available to authorized users.

James J. Gilroy

james.gilroy1@gmail.com

David P. Edwards

david.edwards@sheffield.ac.uk

1 School of Environmental Sciences, University of East Anglia, Norwich NR4 7TJ, UK

2 Department of Animal and Plant Sciences, University of Sheffield, Sheffield S10 2TN, UK
Source-sink studies in tropical regions have predominantly investigated populations exposed to hunting/exploitation, with few examining land-use change. We review policy-relevant arenas where better treatment of source-sink dynamics is a priority: spatial conservation planning, assessments of land-sparing versus land-sharing, the conservation value of selectively logged forests, and species distribution modelling. Finally, we discuss ways to improve understanding of source-sink dynamics, particularly in tropical regions. Failure to detect source-sink patterns across the hyperdiverse tropics could limit the efficacy of conservation practice, leading us to underestimate the severity of human impacts on biodiversity.

Keywords Biodiversity conservation - Tropical ecology · Source sink dynamics $\cdot$ Spatial demography $\cdot$ Land-use change $\cdot$ Habitat quality $\cdot$ Conservation planning $\cdot$ Regional research biases

\section{Introduction}

A large body of applied conservation research seeks to address three broad aims: estimating the impacts of anthropogenic change on native communities, identifying priority sites for protection, and determining management practices that can minimize biodiversity losses or maximise biodiversity recovery $[1,2]$.

At the landscape scale, these goals are often addressed by examining how population density (or presence/absence) varies in space and time, either across gradients of anthropogenic activity or between discrete habitat patches [3, 4]. Common to each of these approaches is an assumption that local population density is a reliable measure of underlying habitat-specific population growth, this being the ultimate determinant of long-term persistence [5]. However, neither 
presence nor density necessarily indicate that a local population is self-sustaining. Intrinsic population growth rates may be below replacement within a given patch or habitat (a 'sink'), but density may be sustained therein by emigration from surrounding 'source' areas that produce a surplus of dispersing individuals [6]. This is a well-established concept in landscape ecology, addressed by a large body of research [7-9].

Despite this, source-sink dynamics remain seldom quantified in applied conservation research [9, 10]. Failure to identify sinks can lead to erroneous or perverse outcomes from conservation decision-making. For example, Wexford Slobs, Ireland, has the largest and most stable subpopulation of the threatened Greenland White-fronted Goose Anser albifrons flavirostris and thus has been identified as the critical location for protection [11]. However, using 29-years of capture-mark-recapture, census and recruitment data to inform integrated population modelling, Weegman et al. [11] showed that Wexford Slobs are actually a sink, with persistence of the subpopulation only possible via high rates of immigration that exceeded emigration in each year. As another example, Gulo gulo wolverines in Norway are hunted in high-density areas where they are assumed to have large productive populations, but analysis of survival and emigration patterns instead reveals that these populations are maintained by compensatory immigration from Sweden, where wolverines are totally protected [12]. Thus, continued hunting in sink areas in Norway may be causing a drain on the southern Scandinavian population as a whole. It remains unclear how often such source-sink patterns are being overlooked in conservation decision-making elsewhere.

A recent review of source-sink research [10] found only 73 studies that provide quantitative evidence for source-sink patterns in nature, from a sample of studies published between 2002 and 2013. The review also revealed evidence of a taxonomic bias towards mammals and birds in source-sink research, and the authors suggested that sources and sinks may be more commonplace in nature than studies suggest [10]. Here, we perform a further review to examine whether there are regional biases in research on source-sink dynamics. Currently, human impacts on biodiversity are at their most severe in tropical regions, where land-use change and habitat degradation are pervasively re-shaping many of the most species-rich ecosystems worldwide [2]. However, it is unclear whether conservation-orientated research in tropical regions is taking sufficient account of the potential for source-sink patterns to arise due to human-driven habitat change. Our review highlights a number of specific policy-relevant questions that are difficult to address without a better understanding of spatial demography. We also examine the factors that are likely to have limited the capacity for source-sink research to be conducted, particularly in tropical regions, and discuss ways to improve the integration of spatial demographics into landscape-scale conservation planning.

\section{The Problem: Presence $\neq$ Persistence}

All populations are exposed to some degree of spatial heterogeneity in biotic and/or abiotic conditions. This heterogeneity can drive spatial variation in vital demographic rates (births and deaths) and, consequently, intrinsic population growth rates $(\lambda)$ across landscapes. Pulliam [6] first proposed that this spatial variation can lead to the emergence of 'sink' areas, where intrinsic growth rates are below replacement $(\lambda<1)$, but persistence is maintained by immigration from surrounding 'source' areas with higher intrinsic growth rates $(\lambda>1)$. Theoretical and empirical studies have shown that source-sink dynamics can emerge in equilibrium populations when there is temporal variability in environmental conditions [13], or when subordinate individuals are forced to occupy poorquality habitats [14]. Perhaps more importantly, sink habitats can emerge when environmental change causes declines in local habitat quality [15-17].

Source-sink systems have clear implications for conservation. In simple terms, spatial conservation planners generally seek to give priority to protecting source habitats, rather than sinks $[18,19]$, provided that sources are temporally consistent and can be identified with confidence [20,21]. Populations exhibiting source-sink dynamics may be prone to local or even global extinction due to stochastic fluctuations [6, 22], making them particularly vulnerable to environmental change. Increases in the prevalence or severity of sinks can drive long-term population declines, as well as increased risk of stochastic extinction. In particular, source-sink populations may contribute to 'extinction debts' associated with environmental change, as source-sink populations can persist for many generations following change before extinction finally occurs [23, 24].

Perhaps the most neglected implication of source-sink dynamics for conservation concerns our approach to measuring the impacts of anthropogenic change on wild species. In source-sink systems, observed patterns of population density often deviate from underlying patterns of demographic productivity. If dispersal rates are high, density within sinks may differ little from density in sources [20]. In some settings, sink density may even exceed that of sources, either due to competitive exclusion by dominant individuals [13] or the decoupling of settlement cues from underlying habitat quality ('ecological traps' [22, 25]). As such, studies that use presence or density indices to infer impacts of habitat change can provide misleading conclusions about conservation priorities in source-sink systems. The consequences of this could be severe; failure to recognize sink habitats could reduce the likelihood that effective conservation measures will be taken to protect a species, while at the same time increases in sink prevalence can greatly exacerbate extinction risk [26].

Despite this conservation significance, and the wealth of interest in source-sink dynamics among theoretical ecologists [27], the number of empirical studies directly demonstrating 
source-sink systems remains small. An important outstanding question is whether there are regional biases in research effort relating to source-sink dynamics. In particular, it is unclear whether source-sink research effort is spatially congruent with areas experiencing maximum environmental change and biodiversity loss (i.e. the tropics [28]). To answer this question, we conducted a further literature review to examine regional and taxonomic biases in research intensity.

\section{Methods: Literature Review Protocol}

We collected studies addressing the source-sink status of one or more wild terrestrial species, using a protocol following the guidelines outlined by Pullin \& Stewart [29]. We searched the online ISI Web of Science database for studies containing the following key words: 'dispersal $\operatorname{sink}(\mathrm{s})$ ', 'source habitat(s)', 'sink habitat(s)', 'source population(s)' OR 'sink population(s)' OR 'mortality sink(s)' OR 'source-sink' (following 10). We refined the search to papers under the categories 'ecology', 'plant science' and 'biodiversity conservation', published between 2003 and 2016, yielding a total of 1195 papers. From these, we selected empirical studies of wild populations, excluding purely theoretical or laboratory-based experiments. We further excluded studies that did not explicitly consider source-sink dynamics or spatial demography, leaving 210 articles for further analysis (Appendix 1). We then classified each of these studies by climate zone (polar/boreal, temperate, subtropical, tropical), biogeographic realm (using realm classification of [30]), and study taxon (invertebrates, fish, herptiles [reptiles and amphibians], birds and mammals).

We further classified studies according to degree of quantitative evidence supporting the presence of source-sink dynamics in the study population. Source-sink dynamics are notoriously difficult to detect from field data [9], requiring quantification of habitat-specific population growth rates $(\lambda)$ using accurate measures of demographic parameters (survival and productivity). However, mark-recapture studies often underestimate survival rates due to emigration outside of sampled areas [9, 31]. Dispersal is also an important component of source-sink dynamics, but is itself difficult to measure at population-relevant scales [32]. Recently, further approaches to detecting source-sink dynamics have been developed using genetic signals, including patterns of asymmetric gene flow, immigration or linkage disequilibrium that are suggestive (but not necessarily confirmatory) of source-sink presence [33, 34]. We classified studies in relation to these three levels of evidence for source-sink dynamics: 1) measurement of habitat-specific demographic rates, 2) measurement of dispersal rates, and 3) genetic approaches. We considered studies that provide two or more of these classes to have 'strong evidence' for source-sink dynamics, and studies providing only one class to provide 'weak evidence'. Some studies proposed source-sink dynamics on the basis of habitatspecific abundance or density patterns, but did not provide any of the three empirical forms of evidence-we classified these as 'speculative' source-sink cases.

Finally, we also classified studies according to type of anthropogenic stressor influencing the species in question. This allowed us to examine the extent to which source-sink research is directly addressing conservation-relevant issues, and explore regional variation in the types of anthropogenic impacts being explored from a source-sink perspective. We used the following categories: agricultural change (including intensification and expansion), fragmentation of natural habitat, logging (including selective and clear-felling), hunting/ exploitation (including fishing, as well as accidental humandriven mortality, e.g. roadkill), species invasions and urbanization. A number of other stressors (including climate change and pollution) were lumped into a further category 'other'. Studies that did not involve systems under the influence of anthropogenic stressors were classified separately. These studies were typically those aiming to elucidate spatial demographic mechanisms in wild populations under natural conditions.

\section{Results: Regional Biases in Source-Sink Research}

Of the 210 studies considered, 151 (71.9\%) were of species inhabiting temperate regions (Fig. 1a). Tropical and subtropical regions accounted for $11.9 \%$ and $12.3 \%$ of studies, respectively, whilst $3.8 \%$ of studies came from polar/boreal zones. Importantly, the proportion of studies speculatively proposing putative source-sink systems based on abundance or density patterns, without supporting demographic or molecular evidence (Fig. 1b), was markedly higher in tropical $(42.3 \%)$ and subtropical $(20 \%)$ regions than in temperate $(5.9 \%)$ and boreal/polar regions ( $0 \%)$. Similarly, the proportion of studies providing strong evidence (Fig. 1b) was markedly lower in tropical (15.3\%) and subtropical (16.0\%) regions than in temperate $(35.1 \%)$ and boreal/polar regions $(50.0 \%)$.

Further patterns of regional bias within climate zones were evident when we looked at the distribution of studies across biogeographic realms (Fig. 2). Studies from the boreal/polar realm were equally split between the Nearctic and Eurasia (Fig. 2a), and these two regions also provided most studies in the temperate zone $(55.6 \%$ and $38.4 \%$, respectively, Fig. 2b). The subtropical and tropical zones were strongly dominated by studies from the Neotropics (52\% and $76 \%$ of studies, respectively, Fig. 2c). Australasia was fairly wellrepresented in the subtropical zone $(28.0 \%)$. The Afrotropical and South Asian realms were poorly represented in both tropical and subtropical zones (Fig. 2), despite having large geographic representation of both climate types. 


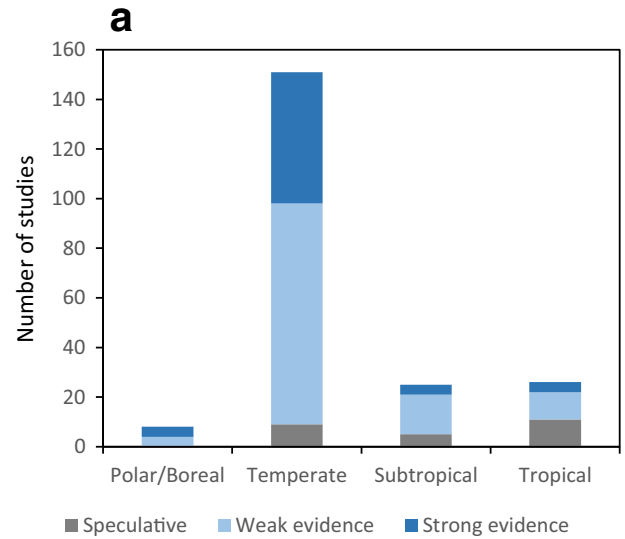

Fig. 1 Number of studies published from 2002-2016 (listed by ISI Web of Science) that propose putative source-sink dynamics within study species, grouped by climate region. Studies are classified according to the level of evidence presented (strong $=2+$ forms of empirical evidence,

Overall, $63.3 \%$ of studies directly addressed cases where populations were impacted by anthropogenic stressors (i.e. were of direct conservation relevance). Studies conducted in tropical regions were more likely to address anthropogenic stressors ( $80.8 \%$ of studies) than studies in the subtropics (60.0\% of studies), temperate regions (62.9\% of studies) and boreal/polar regions ( $25 \%$ of studies).

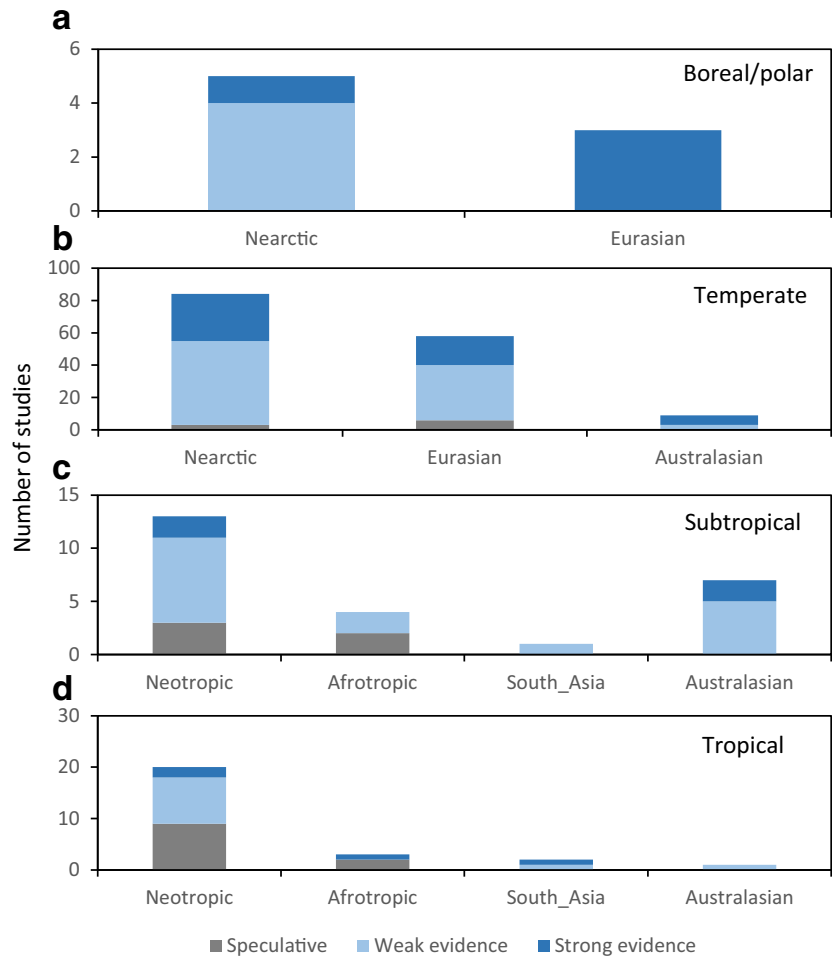

Fig. 2 Numbers of studies proposing putative source-sink dynamics across biogeographic realms, grouped by temperature zone $(\mathrm{a}=$ boreal/ polar, $\mathrm{b}=$ temperate, $\mathrm{c}=$ subtropical, $\mathrm{d}=$ tropical). Studies are classified according to the level of evidence presented (strong $=2+$ forms of empirical evidence, weak $=1$ form of empirical evidence, speculative $=$ patterns of abundance only) b

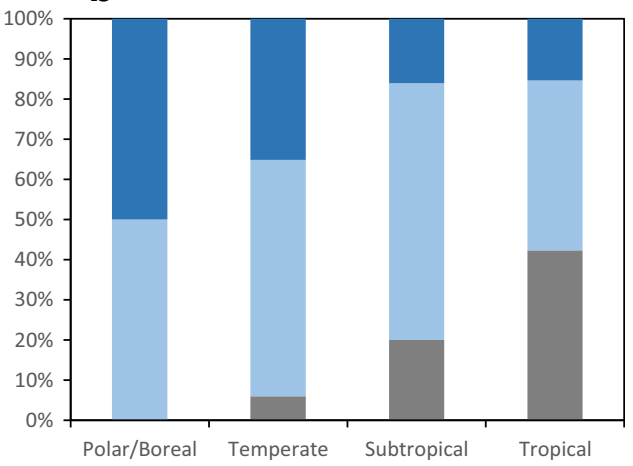

weak $=1$ form of empirical evidence, speculative $=$ patterns of abundance only). Results are shown as raw numbers of studies (a) and proportions of studies in each evidence class (b)

Among specific anthropogenic stressors, the most frequently studied were habitat fragmentation ( $17.1 \%$ of studies), agricultural change $(14.3 \%)$ and hunting/exploitation $(13.3 \%)$. The distribution of these studies across climate zones showed several notable patterns in relation to anthropogenic stressors (Fig. 3). Studies examining agricultural change were primarily conducted in temperate regions (Fig. 3b; $86.7 \%$ of agriculture studies), whilst studies of fragmentation were primarily drawn from temperate and subtropical zones (Fig. 3b \& c; $91.7 \%$ of fragmentation studies), as were studies of invasion effects (Fig. $3 b$ \& c). In the tropics, by contrast, there was a high relative contribution from studies of hunting/exploitation (Fig. 3d; $46.4 \%$ of hunting studies).

Echoing the findings of Furrer \& Pasinelli [10], we also found notable taxonomic biases in study effort, with a predominance of studies on mammals in all climate zones, and birds in particular in temperate zones (Fig. S1). Mammalian studies were particularly dominant in subtropical and tropical regions (37.9\% and $46.7 \%$ of studies, respectively). There were notably few studies on fish, reptiles or amphibians in any climate zone (Fig. S1).

\section{Discussion: What Drives Regional Research Biases?}

Previous reviews have shown that source-sink dynamics receive relatively little empirical research attention overall in global terms $[9,10]$. Our review demonstrates that this scant attention is compounded by a significant skew towards temperate regions in North America and Europe (Figs. 1 and 2). In boreal, tropical and subtropical climate zones, the detection of source-sink patterns has been extremely limited. Tropical and subtropical studies in particular are largely restricted to work in the Neotropics and Australasia (Fig. 2). Moreover, a strikingly high proportion of studies that report potential sourcesink systems in the tropics are largely anecdotal, and do not 


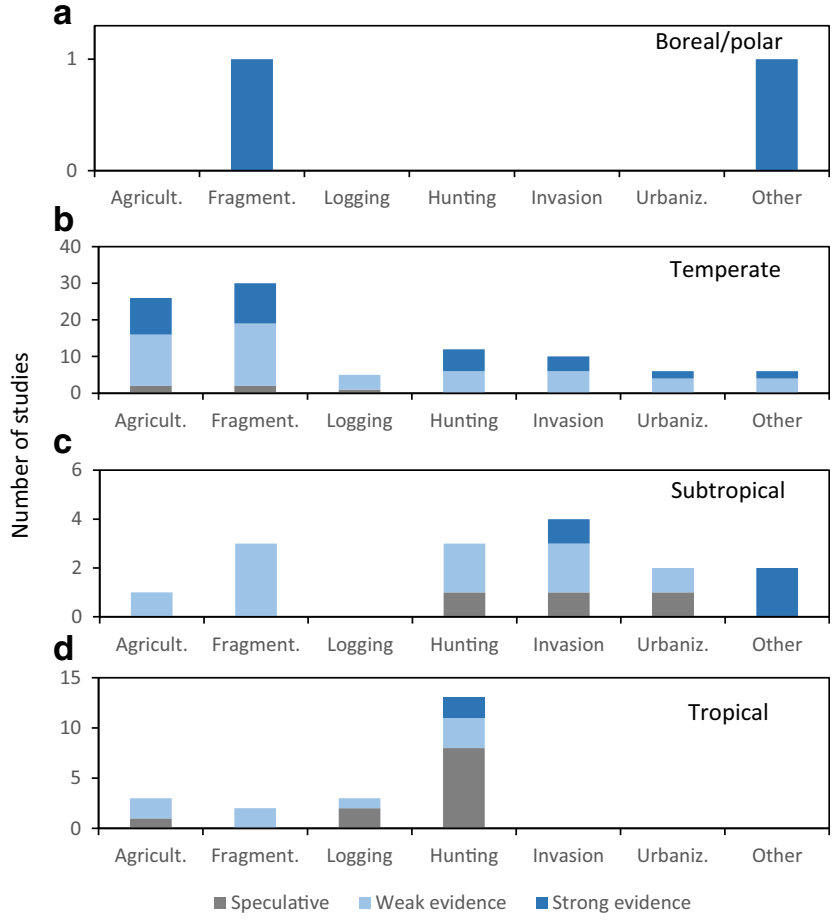

Fig. 3 Numbers of studies addressing source-sink dynamics in populations exposed to anthropogenic stressors, grouped by climate zone $(\mathrm{a}=$ boreal $/$ polar, $\mathrm{b}=$ temperate, $\mathrm{c}=$ subtropical, $\mathrm{d}=$ tropical $)$. Category 'hunting' includes any direct exploitation (e.g. fishing) as well as accidental human-caused mortality (e.g. roadkill). Category 'other' includes climate change, pollution and fire. Studies are classified according to the level of evidence presented (strong $=2+$ forms of empirical evidence, weak $=1$ form of empirical evidence, speculative $=$ patterns of abundance only)

provide rigorous empirical evidence in the form of quantitative analyses of demography, dispersal or molecular signals (Fig. 1; Appendix 1).

One possibility is that this paucity of published research stems from a genuine rarity of source-sink systems in nature, particularly in the tropics. The lack of published studies could then stem from publication bias, rather than lack of research effort, if source-sink studies that return negative results are less likely to get published. However, we contend that this explanation is unlikely. An absence of source-sink dynamics, if rigorously demonstrated, remains a scientifically interesting and important result; we, therefore, do not expect a significant publication bias against negative results in this case (although it cannot be ruled out). Rather, we contend that our review reflects a genuine pattern of regional disparity in research effort.

As stated previously, confirmation of source-sink dynamics in wild populations is extremely difficult, requiring detailed demographic data, dispersal measurements and/or molecular sampling [9], often over large geographic areas. Typically, long time series are also necessary to identify likely sources and sinks with any confidence (e.g. [11]), and to discount the possibility that apparent sinks are actually 'pseudo-sinks', where population growth rates are temporarily suppressed due to density-dependent competition, rather than underlying habitat quality [21]. It seems likely that the difficulty and costliness of collecting the required data to detect a source-sink pattern is the primary reason for the paucity of research. Indeed, given that tropical regions have seen the fastest rates of land-use change and biodiversity loss worldwide over recent decades [35], it is perhaps reasonable to assume that human-driven sink habitats are increasingly emerging within the ranges of many species in tropical regions. Our review suggests that these impacts are currently largely going undetected. This could be contributing to a significant underestimation of biodiversity impacts from anthropogenic change.

It is notable that in the tropics, many studies reporting or speculating on the presence of source-sink dynamics addressed systems impacted by human hunting/exploitation (Fig. 3d), whilst studies of agricultural change were largely limited to temperate regions (Fig. 3b). This is surprising, given that agricultural intensification and expansion are occurring more rapidly in the tropics than anywhere else [28], and are among the most prominent drivers of biodiversity loss in those regions $[28,35,36]$. Much research has examined the biodiversity value of agricultural landscapes in the tropics, particularly low-intensity agroecosystems that often support surprisingly diverse communities [37, 38], and many studies have considered the potential for landscape-scale dispersal and 'spill-over effects' influence community composition in farmed areas [38 and refs therein]. However, our review suggests that relatively few studies have directly examined the spatial demography of populations inhabiting tropical agricultural landscapes, resulting in a paucity of studies reporting source-sink phenomena. Given the growing importance of tropical agricultural landscapes as reservoirs of biodiversity $[39,40]$, this may represent an important research gap.

\section{What are the Conservation Implications of Failures to Detect Source-Sink Patterns?}

Failure to identify source and sink habitats could limit the efficacy of conservation practice, as well as lead to overly optimistic assessments of species vulnerability and the magnitude of anthropogenic impacts on biodiversity [10]. Below, we identify three particular areas of conservation research where the (non-)detection of source-sink patterns is particularly concerning. Given the severe deficiency of source-sink research in the tropics, where human-driven biodiversity losses are currently peaking [36], we focus primarily on the tropics in the following sections, although the issues discussed are broadly relevant in all biomes.

\section{Issue 1: Spatial Conservation Planning}

Conservation planners seek information on source-sink dynamics to identify areas of high importance for population 
persistence (sources), which can then be prioritized for protection. In the absence of detailed information on sources and sinks, decisions are more likely to be made using spatial patterns of density or incidence as proxies for importance. Often, these data are fed into spatial prioritization algorithms (e.g. $[41,42])$ that seek to identify networks of sites that capture the full suite of biodiversity in a region. These algorithms incorporate a consideration of spatial connectivity between sites [43], but generally assume that species density within a site can be taken to indicate population persistence. Clearly, the long-term robustness of protected area networks could be limited if some or all of the prioritized sites for a given species actually represent sinks.

An important current debate in spatial conservation planning concerns the relative importance of protecting primary habitat areas, versus maximising the ecological value of human-modified habitats (e.g. agricultural landscapes [28, 37]). This question has been encapsulated in the 'land-sharing' versus 'land-sparing' debate [39, 40], which remains a fiercely contested question in conservation science [44]. Importantly, quantitative studies that have examined the relative biodiversity benefits of the two strategies in a trade-off framework (e.g. [40, 45]) have invariably used data on population density or incidence across gradients of agricultural intensity (typically measured as yield per hectare). In the trade-off framework proposed by Green et al. [39] and applied by Phalan et al. [40] and others, species with concave densityyield responses are assumed to benefit from land-sharing practices (e.g. low-input farming), whereas species with convex responses benefit more from land-sparing (e.g. protection of large habitat patches). In source-sink systems, however, this may not be the case (Fig. 4), as the population density of a species may remain high in regions of the yield gradient that are actually unlikely to support long-term population growth (Fig. 4). Conservation strategies based on density-yield analyses, therefore, risk being ineffective if strong source-sink dynamics go undetected.

\section{Issue 2: Conservation Value of Selectively Logged Forests}

Selective logging is a major driver of habitat degradation in forests worldwide, and particularly in the tropics [35, 46]. However, evidence suggests that the impacts of logging on biodiversity can be surprisingly small, with high proportions of primary forest species being retained in logged landscapes [47, 48]. This has prompted calls from some conservationists to prioritize the protection of logged forests as a cost-effective conservation strategy [49]. However, it is notable that a high a

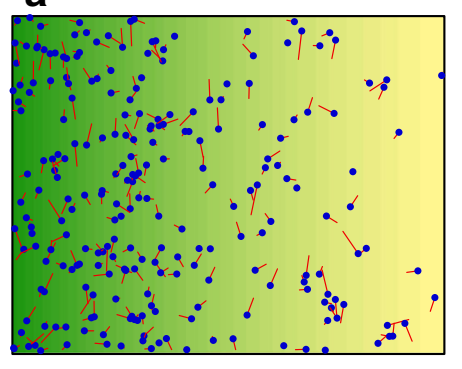

C

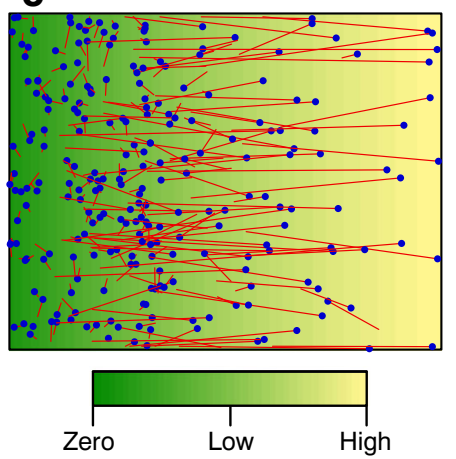

Fig. 4 For a species inhabiting a landscape with varying agricultural intensity ( $\mathrm{a} \& \mathrm{c}$ ), the shape of the relationship between intrinsic population growth rate and agricultural intensity (b \& d) determines whether the species will benefit from a land-sharing approach to conservation (concave relationships) or a land-sparing approach (convex; 39). In (a), the landscape is inhabited by a species that does not exhibit source-sink dynamics (blue dots show breeding individuals, red lines show their dispersal origins). For such a species, abundance is a b

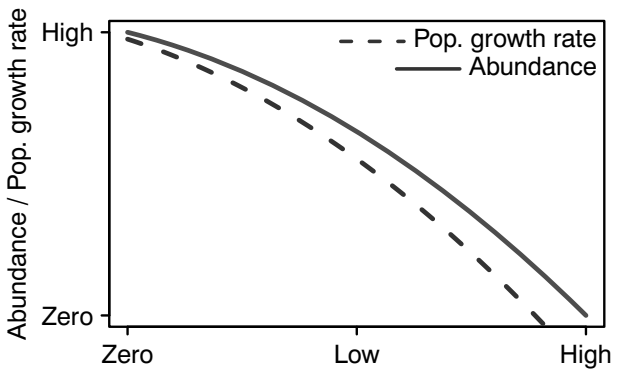

d

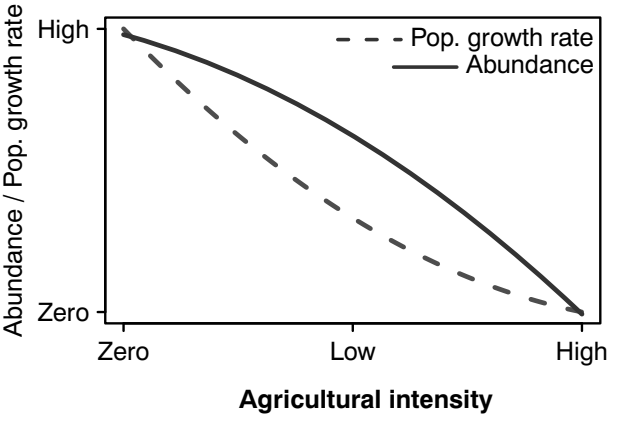

reliable index of underlying population growth rate (b). In (c), the landscape is inhabited by a species exhibiting source-sink dynamics; the overall distribution of breeders (blue dots) is similar to that in (a), but individuals breeding in higher-intensity areas tend to originate from lowintensity sources (red lines). In these circumstances, the abundance relationship indicates that the species would benefit from land-sharing (d, solid line), when, in reality, population growth rates would only be maximised by land-sparing (d, dashed line) 
proportion of studies examining the biodiversity impacts of logging have been conducted in areas adjacent to blocks of intact primary forest [46], and in most cases, impacts are assessed using relative measures of abundance, density or incidence $[47,48]$. As such, inferences about the relative value of logged forests for biodiversity may fail to account for the possibility that logged areas represent sink habitats, where populations are maintained by immigration from surrounding intact forests. Studies examining intrinsic population growth rates within logged forest areas (e.g. [50]) should, therefore, be a high priority for conservationists to provide more robust inferences about the biodiversity value of these degraded forests [28].

\section{Issue 3: Species Distribution Modelling}

Correlative models linking species occurrence patterns to environmental variables are increasingly used in conservation biology for a range of purposes, including spatial planning, the identification of important habitats and sites, estimation of range limits, and the prediction of species responses to climate and habitat change [51]. A wide range of statistical tools are available, each aimed at estimating the bioclimatic niche occupied by a given species. Popular platforms include MaxEnt [52] and other machine-learning algorithms (random forests, boosted regression trees), as well as statistical models such as GAMs [53]. Much interest has been devoted to the refinement of modelling techniques, as well as the selection of environmental variables to use in modelling niche envelopes [51, 54], but less attention has been paid to whether models meaningfully inform us about spatial demography [55]. Invariably, the species data that are fed into species distribution models (SDMs) involve measures of abundance or incidence [51, 55]. In doing so, these approaches again make the assumption that abundance is a reliable measure of local population viability. In source-sink systems, however, SDMs may overestimate the bioclimatic niche of a species by including areas of low suitability for population growth (sinks), and consequently produce unreliable predictions of current and future distributions [56]. Furthermore, any such overestimation will be difficult to detect using standard diagnostic checks that are typically applied to assess model reliability (e.g. area under curve of receiver operating characteristic plots; [57]).

An important use of SDMs in conservation is to predict how species are likely to shift in space in response to climate change [51]. Such predictions are increasingly used to inform conservation planning, with the aim of ensuring that protected area networks are 'climate change ready' by facilitating shifts from currently occupied ranges to areas where conditions may become suitable in the future. Clearly, such exercises rely on accurate model predictions of bioclimatic suitability, which may be compromised if models are naïvely applied to systems with undetected source-sink dynamics. Predictive models also make assumptions about the dispersal capacity of species, allowing estimation of the likelihood that new patches will be colonized by immigrants at range edges [58]. Invariably, these assumptions are based on estimates of mean or maximum dispersal distance, derived from quantitative data where available [58]. However, the likelihood of patch colonization might depend not only on the dispersal behaviour of individuals, but also on the source-sink status of occupied areas at the existing range edge. If habitats at range edges are sinks, the number of potential dispersers moving out into newly suitable areas may be severely reduced. To derive more realistic predictions of species responses to climate change, it may be necessary to model relationships between bioclimatic variables and local intrinsic population growth rates, allowing source-sink patterns to be accounted for within the SDM framework [55]. However, the data requirements of such a model are likely to be prohibitive in most cases.

\section{Moving Forwards: Redoubling Efforts to Detect Source-Sink Patterns in Tropical Landscapes}

Incorporating spatial measures of demographic rates into conservation planning is a key challenge for landscape ecologists, particularly in mega-diverse tropical landscapes undergoing rapid anthropogenic change. Unfortunately, quantifying demographic rates is hugely data-hungry, and is unlikely to ever be achievable for large numbers of taxa or across large regions. As such, a satisfactory solution to the problem of unidentified sources and sinks is likely to be elusive, particularly in the tropics. Nevertheless, useful rules of thumb could be derived from detailed and rigorous studies of model taxa, allowing researchers to identify conditions in which sourcesink patterns are most likely to emerge. More such studies are urgently needed, particularly within tropical environments, to provide an evidence base to better inform our understanding of spatial demography in tropical species that are threatened by current land-use change. The development of more sophisticated integrated population models, capable of bringing together data from multiple sources to estimate demographic rates, could increase our capacity to detect source-sink patterns in a wider range of systems [59, 60]. Improvements in the size, performance and cost-effectiveness of individual tracking technology might also aid considerably in the quantification of survival and dispersal patterns [61].

In some cases, conservation-relevant inferences about source-sink patterns can be made using other approaches. Some researchers, for example, have used the tools of macroecology to make predictions about long-term species persistence following environmental change. Pereira and Daily [62], for example, proposed a framework that combines species-area relationships with estimates of species affinity to primary habitats to derive predictions of extinction likelihood in response to environmental change. This approach, whilst 
falling short of providing direct estimates of source-sink patterns, can provide valuable inferences about the likelihood of species persistence in different landscape scenarios [63].

Other authors have taken a more simplistic approach, inferring likely source-sink patterns on the basis of changes in abundance with increasing distance from likely source habitats $[64,65]$. For example, in cattle farming systems in the Colombian Andes, many bird and dung beetle species can persist in 'wildlife-friendly' low-intensity farmland, but their abundances decline rapidly with distance from contiguous forest edges [38, 64]. This suggests that low-intensity farmland may be a sink for these species, and that land-sparing may consequently be the optimal strategy for conservation, both for species richness and phylogenetic diversity [64, 66]. Although such approaches are again limited in their capacity to confirm source and sink habitats, they can provide important conservation-relevant insights with far lower data requirements than studies of habitat-specific spatial demography. Incorporating information on the spatial configuration of landscapes is, thus, vital in short-term research investigation of the impacts of land-use change and management on biodiversity.

Ultimately, however, genuine advances in our understanding of the impacts of environmental change will require redoubled efforts to measure the relationships between environmental variables and species' birth, death and dispersal rates. Gathering such information typically requires intensive field-based research, using mark-recapture and/or telemetry approaches to estimate relevant survival and dispersal parameters. Only by quantifying spatial and temporal variation in these key parameters will we be able to identify the set of environmental characteristics that support positive population growth at landscape scales. Such detailed demographic information is essential if we are to fully understand how to optimise conservation actions for any given species.

\section{Conclusion}

This review highlights the current paucity of research into source-sink systems, particularly in tropical and subtropical regions. The tropics house the highest levels of biodiversity [67], and currently face the highest rates of habitat conversion and degradation [35], placing tropical regions at the epicentre of the biodiversity crisis. Researchers are struggling to document patterns of biodiversity loss in response to rapid rates of land-use change [28], and conservation decisions are continually being made on the basis of limited data [68]. Much of current conservation practice is informed by patterns of species abundance or occurrence, but there are many circumstances in which these patterns can provide a misleading picture of the long-term suitability of habitats. Our review indicates that a significant increase in research effort is necessary, particularly in tropical regions, to measure how demographic rates and dispersal patterns are changing across landscapes in response to anthropogenic impacts.

Acknowledgements We thank Dr. Heather Bird Jackson for inviting us to write this review.

\section{Compliance with Ethical Standards}

Conflict of Interest Dr. James Gilroy and Dr. David Edwards have no conflicts of interest to declare.

Human and Animal Rights and Informed Consent This article does not contain any studies with human or animal subjects performed by any of the authors.

\section{References}

1. Meine C, Soule M, Noss RF. "A Mission-Driven Discipline": the Growth of Conserv Biol. Conserv Biol. 2006;20:631-51.

2. 2 Fiedler PL (ed). Conservation Biology: the theory and practice of nature conservation preservation and management. Springer; 2012.

3. Johnson MD. Measuring habitat quality: a review. Condor. 2007;109:489-504.

4. Gaillard JM, Hebblewhite M, Loison A, Fuller M, Powell R, Basille $\mathrm{M}$, et al. Habitat-performance relationships: finding the right metric at a given spatial scale. Phil Trans Roy Soc B. 2010;365:2255-65.

5. Van Horne B. Density as a misleading indicator of habitat quality. J Wildlife Manag. 1983;47:893-901.

6. Pulliam HR. Sources, sinks, and population regulation. Am Nat. 1988;132:652-61.

7. Holyoak M, Leibold MA, Holt RD. Metacommunities: spatial dynamics and ecological communities. University of Chicago Press; 2005.

8. Dunning JB, Danielson BJ, Pulliam HR. Ecological processes that affect populations in complex landscapes. Oikos. 1992;65:169-75.

9. Runge JP, Runge MC, Nichols JD. The role of local populations within a landscape context: defining and classifying sources and sinks. Am Nat. 2006;167:925-38.

10. Furrer RD, Pasinelli G. Empirical evidence for source-sink populations: a review on occurrence, assessments and implications. Biol Rev. 2015;91:782-95.

11. Weegman MD, Bearhop S, Fox AD, Hilton GM, Walsh AJ, McDonald JL, et al. Integrated population modelling reveals a perceived source to be a cryptic sink. J Anim Ecol. 2016;85:467-75.

12. Gervasi V, Brøseth H, Nilsen EB, Ellegren H, Flagstad Ø, Linnell JD. Compensatory immigration counteracts contrasting conservation strategies of wolverines (Gulo gulo) within Scandinavia. Biol Conserv. 2015;191:632-9.

13. Holt RD. Population dynamics in two-patch environments: some anomalous consequences of an optimal habitat distribution. Theor Pop Biol. 1985;28:181-208.

14. Morris DW, Lundberg P, Ripa J. Hamilton's rule confronts ideal free habitat selection. Proc Royal Soc Bs. 2001;268:921-4.

15. Donovan TM, Thompson FR, Faaborg J, Probst JR. Reproductive success of migratory birds in habitat sources and sinks. Conserv Biol. 1995;9:1380-95.

16. Woodroffe R, Ginsberg JR. Edge effects and the extinction of populations inside protected areas. Science. 1998;280:2126-8.

17. Robertson BA, Rehage JS, Sih A. Ecological novelty and the emergence of evolutionary traps. Trends Ecol Evol. 2013;28:552-60.

18. Margules CR, Pressey RL. Systematic conservation planning. Nature. 2000;405:243-53. 
19. Carroll C, Noss RF, Paquet PC, Schumaker NH. Use of population viability analysis and reserve selection algorithms in regional conservation plans. Ecol Appl. 2003;13:1773-89.

20. Howe RW, Davis GJ, Mosca V. The demographic significance of 'sink'populations. Biol Conserv. 1991;57:239-55.

21. Watkinson AR, Sutherland WJ. Sources, sinks and pseudo-sinks. J Anim Ecol. 1995;64:126-30.

22. Battin J. When good animals love bad habitats: ecological traps and the conservation of animal populations. Conserv Biol. 2004;18: 1482-91.

23. Carroll C, Noss RF, Paquet PC, Schumaker NH. Extinction debt of protected areas in developing landscapes. Conserv Biol. 2004;18: 1110-20.

24. Hylander K, Ehrlén J. The mechanisms causing extinction debts. Trends Ecol Evol. 2013;28:341-6.

25. Delibes M, Ferreras P, Gaona P. Attractive sinks, or how individual behavioural decisions determine source-sink dynamics. Ecol Lett. 2001;4:401-3.

26. Hanski I. Metapopulation dynamics. Nature. 1998;396:41-9.

27. Loreau M, Daufresne T, Gonzalez A, Gravel D, Guichard F, Leroux SJ, et al. Unifying sources and sinks in ecology and Earth sciences. Biol Rev. 2013;88:365-79.

28. Chazdon RL, Harvey CA, Komar O, Griffith DM, Ferguson BG, Martínez-Ramos M, et al. Beyond reserves: A research agenda for conserving biodiversity in human-modified tropical landscapes. Biotropica. 2009;41:142-53.

29. Pullin AS, Stewart G. Guidelines for systematic review in conservation and environmental management. Conserv Biol. 2006;20: 1647-56.

30. Olson DM, Dinerstein E, Wikramanayake ED, Burgess ND, Powell GVN, Underwood ECD, et al. Terrestrial ecoregions of the world: a new map of life on Earth. Bioscience. 2001;51:933-8.

31. Gilroy JJ, Virzi T, Boulton RL, Lockwood JL. A new approach to the "apparent survival" problem: estimating true survival rates from mark-recapture studies. Ecology. 2012;93:1509-16.

32. Nathan R. The challenges of studying dispersal. Trends Ecol Evol. 2001;16:481-3.

33. Storfer A, Murphy MA, Evans JS, Goldberg CS, Robinson S, Spear SF, et al. Putting the 'landscape' in landscape genetics. Heredity. 2007;98:128-42.

34. Peery MZ, Beissinger SR, House RF, Bérubé M, Hall LA, Sellas A, et al. Characterizing source-sink dynamics with genetic parentage assignments. Ecology. 2008;89:2746-59.

35. Asner GP, Rudel TK, Aide TM, DeFries R, Emerson R. A contemporary assessment of change in humid tropical forests. Conserv Biol. 2009;23:1386-95.

36. Pimm SL, Jenkins CN, Abell R, Brooks T, Gittleman JL, Joppa LN, et al. The biodiversity of species and their rates of extinction, distribution, and protection. Science. 2014;344:1246752.

37. Fischer J, Brosi B, Daily GC, Ehrlich PR, Goldman R, Goldstein J, et al. Should agricultural policies encourage land sparing or wildlife-friendly farming? Frontiers Ecol Envir. 2008;6:380-5.

38. Gilroy JJ, Edwards FA, Medina Uribe CA, Haugaasen T, Edwards DP. Surrounding habitats mediate the trade-off between landsharing and land-sparing agriculture in the tropics. J Appl Ecol. 2014;51:1337-46.

39. Green RE, Cornell SJ, Scharlemann JP, Balmford A. Farming and the fate of wild nature. Science. 2005;307:550-5.

40. Phalan B, Onial M, Balmford A, Green RE. Reconciling food production and biodiversity conservation: land sharing and land sparing compared. Science. 2011;333:1289-91.

41. Ball IR, Possingham HP, Watts M. Marxan and relatives: software for spatial conservation prioritisation: quantitative methods and computational tools. Oxford University Press; 2009.
42. Lehtomäki J, Moilanen A. Methods and workflow for spatial conservation prioritization using Zonation. Environ Model Softw. 2013;47:128-37.

43. Lehtomäki J, Tomppo E, Kuokkanen P, Hanski I, Moilanen A. Applying spatial conservation prioritization software and highresolution GIS data to a national-scale study in forest conservation. Forest Ecol Manag. 2009;258:2439-49.

44. Kremen C. Reframing the land-sparing/land-sharing debate for biodiversity conservation. Annals NY Acad Scis. 2015;1355:52-76.

45. Edwards DP, Gilroy JJ, Woodcock P, Edwards FA, Larsen TH, Andrews DJ, et al. Land-sharing versus land-sparing logging: reconciling timber extraction with biodiversity conservation. Glob Change Biol. 2014;20:183-91.

46. Edwards DP, Tobias JA, Sheil D, Meijaard E, Laurance WF. Maintaining ecosystem function and services in logged tropical forests. Trends Ecol Evol. 2014;29:511-20.

47. Edwards DP, Larsen TH, Docherty TD, Ansell FA, Hsu WW, Derhé MA, et al. Degraded lands worth protecting: the biological importance of Southeast Asia's repeatedly logged forests. Proc Roy Soc B. 2011;278:82-90

48. Edwards DP, Magrach A, Woodcock P, Yinqiu J, Lim NTL, Edwards FA, et al. Selective-logging and oil palm: multi-taxon impacts, biodiversity indicators, and trade-offs for conservation planning. Ecol Appl. 2014;24:2029-49.

49. Fisher B, Edwards DP, Giam X, Wilcove DS. The high costs of conserving Southeast Asia's lowland rainforests. Frontiers Ecol Envir. 2011;9:329-34.

50. Srinivasan U, Hines JE, Quader S. Demographic superiority with increased logging in tropical understorey insectivorous birds. J Appl Ecol. 2015;52:1374-80.

51. Elith J, Leathwick JR. Species distribution models: ecological explanation and prediction across space and time. Ann Rev Ecol Evol Sys. 2009;40:677-97.

52. Phillips SJ, Dudík M. Modeling of species distributions with Maxent: new extensions and a comprehensive evaluation. Ecography. 2008;31:161-75.

53. Austin M. Species distribution models and ecological theory: a critical assessment and some possible new approaches. Ecol Model. 2007;200:1-19.

54. Araujo MB, Guisan A. Five (or so) challenges for species distribution modelling. J Biogeogr. 2006;33:1677-88.

55. Schurr FM, Pagel J, Cabral JS, Groeneveld J, Bykova O, O'Hara $\mathrm{RB}$, et al. How to understand species' niches and range dynamics: a demographic research agenda for biogeography. J Biogeog. 2012;39:2146-62.

56. Holt RD. Bringing the Hutchinsonian niche into the 21st century: ecological and evolutionary perspectives. Proc Nat Acad Sci. 2009;106(S2):19659-65.

57. Anderson RP, Lew D, Peterson AT. Evaluating predictive models of species' distributions: criteria for selecting optimal models. Ecol Model. 2003;162:211-32.

58. Kearney M, Porter W. Mechanistic niche modelling: combining physiological and spatial data to predict species' ranges. Ecol Lett. 2009;12:334-50.

59. Rhodes JR, Ng C, de Villiers DL, Preece HJ, McAlpine CA, Possingham HP. Using integrated population modelling to quantify the implications of multiple threatening processes for a rapidly declining population. Biol Conserv. 2011;144:1081-8.

60. Hostetler JA, Chandler RB. Improved state-space models for inference about spatial and temporal variation in abundance from count data. Ecology. 2015;96:1713-23.

61. Jønsson KA, Tøttrup AP, Borregaard MK, Keith SA, Rahbek C, Thorup K. Tracking animal dispersal: from individual movement to community assembly and global range dynamics. Trends Ecol Evol. 2016;31:204-14. 
62. Pereira HM, Daily GC. Modeling biodiversity dynamics in countryside landscapes. Ecology. 2006;87:1877-85.

63. Mendenhall CD, Sekercioglu CH, Brenes FO, Ehrlich PR, Daily GC. Predictive model for sustaining biodiversity in tropical countryside. Proc Nat Acad Sci. 2011;108:16313-6.

64. Gilroy JJ, Woodcock P, Edwards FA, Wheeler C, Medina Uribe CA, Haugaasen T, et al. Optimizing carbon storage and biodiversity protection in tropical agricultural landscapes. Glob Change Biol. 2014;20:2162-72.

65. Matos FAR, Magnago LFS, Gastauer M,Carreiras JMB, Simonelli M, Meira-Neto JAA, et al. Effects of landscape configuration composition and edges on phylogenetic diversity of trees in a highly fragmented tropical forest. J Ecol. 2016 in press

66. Edwards DP, Gilroy JJ, Thomas GH, Medina CA, Haugaasen T. Land-sparing agriculture best protects avian phylogenetic diversity. Curr Biol. 2015;25:2384-91.

67. Jenkins CN, Pimm SL, Joppa LN. Global patterns of terrestrial vertebrate diversity and conservation. Proc Nat Acad Sci. 2013;110:E2602-10.

68. Gardner TA, Barlow J, Parry LW, Peres CA. Predicting the uncertain future of tropical forest species in a data vacuum. Biotropica. 2007;39:25-30. 